\title{
Thai Employees' Perception Towards Organizational Crisis Preparedness
}

\section{Dr. Chaiyaset Promsri}

Faculty of Business Administration, Rajamangala University of Technology Phra Nakhon Email: Chaiyaset.p@rmutp.ac.th

\section{Doi:10.5901/mjss.2014.v5n14p41}

\section{Abstract}

As numerous disasters and crises occurred in past years, organizations, regardless of organizational types, must be ready and prepared for upcoming incidents, which constantly occur and setback organizations to accomplish goals. The result of unprepared crisis management plan may lead an organization to confront with low morale of workforce, low productivity and profitability, physical damage, and even death of employees. Therefore, preparedness of crisis management is a vital key for business success. The objectives of this study were to examine perceived organizational crisis preparedness of Thai employees, and to compare the differences on organizational and demographic characteristics of employees. Data were collected from 233 employees in a paper packaging company in Thailand by using the self-administrated questionnaire. The results of independent t-test analysis indicated significant mean differences in employment state and education in crisis. In contrast, the finding showed no significant mean difference in work experience. Limitations and further study recommendations were also discussed.

Keywords: Crisis management, Organizational crisis preparedness, Crisis preparation

\section{Introduction}

Disaster Preparedness and crisis management have long been an interesting topic discussed in current research. Today's Businesses have been continually facing uncertainties and vulnerabilities and affected by natural disasters and organizational crises (Ulmer, Sellnow, and Seeger, 2007). Crisis incidents can threaten and occur in any stage of organization's life cycle (Hargis and Watt, 2010). As numerous disasters and crises occurred in past years, organizations, regardless of organizational types, must be ready and prepared for upcoming incidents, which constantly occur and setback organizations to accomplish goals.

Organizations are now becoming increasingly more multifaceted and interdependent to effectively respond to rapid change and a highly competitive environment. To cope with the unforeseen events effectively, businesses must be prepared crisis management plan to ensure that everything will move to the right direction. Augustine (1995) reported the survey of Fortune 500 CEOs that $89 \%$ of them perceived crises as unavoidable events, and $97 \%$ of them were confident to handle crises effectively if one happened. However, a half of them admitted that they failed to have a preparation for crisis management plan. Businesses failed to prepare crisis management plan may cause irreparable damage and be difficult to achieve organizational goals (Meznar, 2012). Results of unprepared organizations for crises and disasters significantly showed losses and damages of lives, assets, properties, and reputations. Effective crisis management has increasingly become significant for today's organizations (King, III, 2002). Having crisis management plan in place, therefore, can help minimize the danger to an organization and maximize every possible opportunity (Devlin, 2006).

Crisis management is defined as "an organization's pre-established activities and guidelines for preparing and responding to significant catastrophic events or incidents (i.e., fires, earthquakes, severe storms, workplace violence, kidnappings, bomb threats, acts of terrorism, etc.) in a safe and effective manner" (Lockwood, 2005, p. 2). Parsons (1996) noted that crisis management is a combination of intuition, knowledge, experience, and time to make decisions when facing the problem. Crisis management requires anticipating, indicating, studying, and taking actions upon crisis events, and founding procedures that would allow an organization to mitigate or deal with crises effectively (McCray, Gonzalez, and Darling, 2010). According to the recent survey on crisis preparedness, $60 \%$ of companies reported that their companies had crisis response plan, but $32 \%$ of them did not know the last time their companies reviewed or revised the plan (Pillsburylaw, 2011). This finding supports the crisis management survey of Audit Executive Center in 2010 , which indicated that $26 \%$ of organizations had a plan that applies to all crises. The result of unprepared crisis management plan may lead an organization to confront with low morale of workforce, low productivity and profitability, physical damage, and even death of employees. Therefore, preparedness of crisis management is a vital key for 
business success because "the best crisis is the one that has been prevented" (Barton, p. 18).

\section{Background and Significance Problems}

A crisis is "a low-probability, high-impact event that threatens the viability of the organization and is characterized by ambiguity of cause, effect, and means of resolution, as well as by a belief that decisions must be made swiftly" (Pearson and Clair, 1998, p. 60). Organizational crises are perceived as dynamic processes including three essential stages: a precrisis stage, a crisis stage, and a post-crisis stage (Johansen, Aggerholm, and Frandsen, 2012). A crisis can come in two major forms, which are natural disasters and man-made disaster (Lussier and Achua, 2007). Any forms of these major crises can cause three major damages for companies, which comprised of public safety and security, financial loss, and reputation loss (Coombs, 2007). As most of crisis incidents occur suddenly and devastatingly, organizations are required to make a quick decision and take immediate reaction to mitigate problems (Daft and Marcic, 2009). However, organizations somehow may not have sufficient information to make an effective decision (Borodzicz, 2005) so that people who are responsible for decision-making strive to respond to any crisis with less information, and eventually come up with the failure.

Recent research indicated that organizations are unlikely to survive in business if they are unable to recover from any major crisis within 10 days (Daft and Marcic, 2009). It is therefore very important for every organization to understand and be prepared for a crisis. The SHRM 2005 Disaster Preparedness Survey Report designated that more than 50\% of organizations generated or modified their disaster and crisis preparedness plan after September 11 incident whereas the rest of them did not (Lockwood, 2005). The results of this survey report reemphasize the notions and reflect attitudes of some companies as they refused that crisis or disaster events can happen in their organization. Moreover, according to recent crisis preparedness survey, $56 \%$ of response companies revealed that they were somewhat confident that their companies were able to cope with a major crisis effectively, whereas $13 \%$ of them were less confident (Pillsburylaw, 2011). The finding of this survey can reflect the preparedness of crisis in organizations. The study of Johansen, Aggerholm, and Frandsen (2012) examined perceived organizational crisis management and plan between executives and employees. This study found that employees felt betrayed, ashamed, and panic when they perceived crises. Furthermore, they also discovered that employees needed more information, and had a higher perception of insecurity. These findings display the lack of having crisis prevention and preparation. The result of this study can be supported by the report of crisis preparedness survey in 2011 in which $64 \%$ of response companies did not conduct annual training drills or exercises to ensure all employees know what to do when crises occurred. Blythe (2004) identified five reasons that cause executives and companies fail to appropriately protect and prevent them from crisis as follows: denying that it can happen; reluctantly prioritize crisis preparedness; being unaware of risks inherent to business; ignoring warning signs; and relying on weak, unproven plans. These reasons are critical to organizations to realize that if they are to survive in crisis, they cannot ignore any of this mismanagement and must be willing to solve all of these problems. Johansen and Frandsen noted that organizational crisis can be evaded if the organizations have crisis prevention and preparation in place (as cited in Johansen, Aggerholm, and Frandsen, 2012). To measure an organizational effectiveness in coping with crisis situation, numerous studies tend to focus on the outcomes, yet crisis outcomes either success or failure are reflected by crisis preparedness. Thus, to assess effective crisis management in an organization, crisis preparedness is a vital key for measurement.

The development of crisis management over the past decades has been obviously focused on two distinct approaches, which are crisis as unavoidability and as pro-active crisis prevention (Jaques, 2010). Even though many scholars agree that crisis is inevitable, they argue that crisis can be anticipated and mitigated the consequence of crisis. Research demonstrated that crisis management process begins with the perceptions of leaders toward uncertainties and vulnerabilities, leading to find out ways to prevent or mitigate those crises (Smits and Ally, 2003). However, crisis cannot be prevented or reduced by leaders' response solely, but it requires the collaboration of all entities in an organization. To ensure that people in an organization are able to handle crisis properly when it occurs, knowledge and ideas about crisis must be provided to responsible employees beforehand.

Pearson and Clair (1998) proposed a comprehensive descriptive of crisis management process model, which encompasses a preevent environment, perceptual and organizational characteristics, and postevent reactions, responses, and outcomes. To empirically measure the preevent environment as with low likelihood but high vulnerability, research has some limitations on identifying organizational readiness for crisis or disaster if visible catastrophes did not happen in a specific setting. Researchers had no ideas whether the preevent preparedness was in place until noticeable damage occurred. If no visible damage occurred, it may be impractical to assess preevent crisis preparedness. On the other hand, if visible damage happened, researchers may be able to trace back to assess the crisis preparedness of a 
specific organization. According to Pearson and Clair (1998), the crisis management process focused on three crucial preevent factors, which are environmental context including institutionalized practices and industry regulations, executive perceptions about risk, and adoption of organizational crisis management preparations. As this model placed its emphasis on crisis management outcomes either success or failure, these three contributing factors had affected and determined the degree of organizational success and failure from crisis. Fowler, Kling, and Larson (2007) used the concepts of Pearson and Clair's work to develop research hypotheses, which aimed to explore perceived organizational crisis preparedness. They focused on five types of crises that could happen in the organizations, which consisted of secondary terrorist attack, natural disaster, major terrorist attack, accidental disaster, and workplace violence. However, this study had limitations on the sample in which the majority of respondents were from the alumni graduate from accredited business colleges in the U.S. This study, therefore, recommended doing the study on perceptions of crisis preparedness in other parts of world. Besides, this study also suggested further study to explore a group of specific industries such as airlines, manufacturing, health care, high-tech, transportation, and so on rather than the broad range of organization's types such as profit or nonprofit organizations. Therefore, assessing preevent environment of crisis management is important for an organization to ensure that crisis preparedness is in place and ready to be implemented when crisis occurs.

Although numerous studies attempted to investigate the readiness of crisis management in different settings (Chong and Nyaw, 2002; Ocal, Oral, and Erdis, 2006; Fowler, Kling, and Larson, 2007; Najafbagy, 2011; Johansen, Aggerholm, and Frandsen, 2012), there is still a few research focusing on preevent preparedness, which is necessary to empirically assess the crisis management process and results. Moreover, the research on organizational crisis preparedness in Thailand is scant and somewhat new, and needs more empirical studies in this area. Therefore, the objectives of this study are (1) to examine perceived organizational crisis preparedness of Thai employees; and (2) to compare the differences on organizational and demographic characteristics of employees.

\section{Propositions}

According to Pearson and Clair (1998), the crisis management process focused on three crucial preevent factors, which are environmental context including institutionalized practices and industry regulations, executive perceptions about risk, and adoption of organizational crisis management preparations. As this model placed its emphasis on crisis management outcomes either success or failure, these three contributing factors had affected and determined the degree of organizational success and failure from crisis. Fowler, Kling, and Larson (2007) used the concepts of Pearson and Clair's work to develop research hypotheses, which aimed to explore perceived organizational crisis preparedness. This study attempted to compare the perception of preparedness for a crisis prior to the actual event occurring focusing management levels, organizational size, type of industry, and population density of an organization's location. The results indicated that the top management had a higher perception of crisis preparedness than typical employees. Based on these assumptions, this present study therefore develops organizational and demographics variables to measure the differences on perceived organizational crisis preparedness of employees in a chosen company in Thailand. Consequently, this present study proposes hypotheses that are more exploratory in nature and more specific as the followings:

Hypothesis 1: Executives will have a higher perception of organizational crisis preparedness than the employee.

Hypothesis 2: Employees with more work experience will have higher perception of organizational crisis preparedness than employees with less work experience.

Education in crisis management such as training and workshop is perceived as a vital key that leads to effective crisis preparedness. Training helps strengthen employees' preparedness, and ensure that they will do what they should when a crisis occurs (Bernstein, 2012). Previous research has examined the positive relationship between level of crisis education of the manager and having crisis management plan (Johansen, Aggerholm, and Frandsen, 2012). This finding, however; did not indicate the relationship between level of crisis education and the perception of organizational crisis preparedness. Furthermore, past research on organizational crisis preparation attempted to explore the difference of perception between the type of organization, number of organization employees, and location of organization, but the scrutiny on the difference of acquired crisis education of respondent on perceived organizational crisis preparedness is seldom emphasized. As a result, this present study develops a hypothesis as the following:

Hypothesis 3: Employees with education in crisis management will have a higher perception of organizational crisis preparedness than employees with no education in crisis management. 


\section{Delimitation}

The geographic area and setting, and samples of this study were limited to only one specific company in Thailand. Respondents from a selected company based on probability sampling technique, must agree to participate in this study prior to completing the questionnaire. The survey instrument was developed in Thai version used for only Thai employees who worked in a chosen company. The questionnaire was developed to measure perception of crisis preparedness in organizations. Respondents must be able to speak, read, and write in Thai fluently to complete the questionnaire. To protect the rights of participants, informed consent procedures were implemented.

\section{Conceptual Framework}

Based on literature review, this research develops conceptual framework that helps answer research hypotheses. Organizational and demographic characteristics were created based on the studies of Pearson and Clair (1998); Fowler, Kling, and Larson (2007); Johansen, Aggerholm, and Frandsen (2012), which were developed as independent variables. For perceived organizational crisis preparedness in a paper packaging company, this present study embraced organizational crises preparedness variables proposed by Fowler, Kling, and Larson (2007); Dinkin (2007); Bernstein (2012) to develop dependent variables.

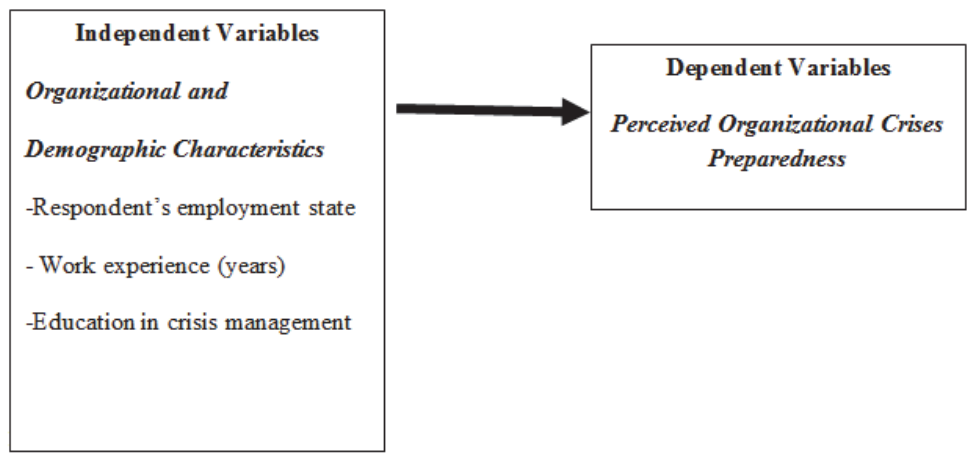

\section{Literature Review}

\subsection{Definition and Types of Crisis}

Crisis preparedness and prevention is part of crisis management plan in which attempts to reduce the unexpected incident that could occur in an organization. Ulmer, Sellnow, and Seeger (2007) offer definition of organizational crisis as "a specific, unexpected, and nonroutine event or series of events that create high levels of uncertainty and threaten or are perceived to threaten an organization's high-priority goals" (p. 7). In this present study, definition of organizational crisis proposed by Ulmer, Sellnow, and Seeger (2007) is applied.

Crisis events disrupted the operations of organizations can be caused by a broad array of incidents, such as industrial accidents, contamination, corporate social irresponsibility, financial collapse, or fraud and product liability cases (Hargis and Watt, 2010). In sum, it becomes clear that a crisis can come in two major forms, which are natural disasters and man-made disaster (Lussier and Achua, 2007). Any forms of these major crises can cause three major damages for companies, which comprised of public safety and security, financial loss, and reputation loss (Coombs, 2007). The consequences of these damages indicate the effectiveness of crisis management plan. Research showed that successful anticipating crisis events require effective planning and strategic leadership, mastery of organizational development, and clear decision process (Hargis and Watt, 2010). Furthermore, role and responsibility clarity is a prerequisite to behavioral readiness while being involved with crisis (Smits and Ally, 2003). In the case of crisis management, if people in organizations are understood what needs to be done before, during, and after crises, organizations are more likely to cope with crises effectively, and recover from crises more hastily.

Pearson and Clair (1998) proposed an array of organizational crises as follows: extortion, hostile takeover, product tampering, vehicular fatality, copyright infringement, environmental spill, computer tampering, security breach, executive 
kidnapping, product/ security breach, executive kidnapping, product/ service boycott, work-related homicide, malicious rumor, natural disaster that destroys organizational information base, bribery, information sabotage, workplace bombing, terrorist attack, plant explosion, sexual harassment, escape of hazardous materials, personnel assault, assault of customers, product recall, counterfeiting, and natural disaster that destroys that eliminates key stakeholders (p. 60).

\subsection{Crisis Preparedness}

Preparedness is undertaken prior to the occurrence of crisis. McEntire noted that preparedness can be identified in three different perspectives. The first perspective of preparedness can be exemplified by Gillespie and Streeter as "planning, resource identification, warning systems, training and simulations, and other predisaster actions intended to improve the safety and effectiveness of community response to disaster." The second perspective considers preparedness as an activity to anticipate the likelihoods and develop possible ways to cope with them. The third perspective views preparedness as establishing capabilities and promptness to increase the effective reaction (as cited in Eriksson, 2010). To blend these three perspectives, crisis preparedness are understood as undertaken activities developed before crisis occurs in the extent to foresee the likelihoods and create the possible solutions to deal with them as well as to repeatedly develop abilities and readiness of people to respond those crises effectively. These crisis preparation activities incorporate planning, resource identification and allocation, warning systems setup, and crisis education and training.

\subsection{Related Research on Crisis Management}

Chong and Nyaw (2002) used a seven-page questionnaire to measure crisis preparedness of Hong Kong companies. There were four groups of respondents involved in this study including manufacturing firms listed under Member's Directory of Federation of Hong Kong Industries, Members' Directory, Hong Kong American Chamber of Commerce, Directory of Chinese Executives Club, Hong Kong Management Association, and senior corporate executives registered in an executive MBA program of a famous university in Hong Kong. The first three groups were sent the questionnaire to the CEOs or general managers through mail whereas the forth group did the survey in class. A response rate of this study was $25.63 \%$, which was considered high when compared to other studies of companies in both Western and Eastern. According to the questionnaire, organizational and demographic characteristics were divided into 7 categories including type of industry (manufacturing or non-manufacturing), ownership (foreign, local/China, or joint venture), respondents age (years), gender, education, rank (top management or senior management), and work experience (years). For rationale for crisis and contingency planning, the findings indicated that the most reason for initiating the crisis management plan was "assuring the continuation of business during a crisis" (76.2\%). For crisis management team, the most frequently represented functional area of crisis management team was corporate safety and security $(76.2 \%)$. In addition, $71.4 \%$ of respondents reported that crisis management in their firms handled by internal staff only, and $38.1 \%$ of respondents described that senior manager was a designated spokesperson during the crisis. For assessment and improvement of crisis management plan, this study showed that there were two important factors for improving crisis management plan, which consisted of "continuous review of the plan to identify and correct weakness" and "establishing a more effective early warning system with reasonable trigger point for monitoring crisis."

Ocal, Oral, and Erdis (2006) investigated the degree of crisis management application throughout the industry, primarily focusing on the results during the economic crisis in 2001. This study used a 25-question of survey questionnaire to gather information from the top management of 120 construction companies. Thurstone's paired comparisons, Pearson's chi-square test, and Fisher's exact test, were used as statistical analysis to analyze the data. Findings showed that the most important causes of environmental and organizational factors that may lead to crises were prioritized by the top management of Turkish construction companies comprised of government policies, instable market conditions, lack of financial support, inadequacy of human resources, and insensitivity of company members towards company objectives, respectively. When asked about their perception of crisis, the top management described crisis as uncertainty (60\%), risk (53\%), and instability (53\%), respectively. Moreover, results indicated that only a few companies applied crisis management systematically, and the extent of crisis management implementation varied depending on the size and structure of the companies.

Fowler, Kling, and Larson (2007) examined perceptions of organizational preparedness for coping with a major crisis or disaster. They developed research hypotheses based on a comprehensive descriptive model of crisis management process proposed by Pearson and Clair. Fowler et al. (2007) placed their emphasis on environment context, which included perceptions of executives, location of organizations in terms of population density, types of organizations, and the numbers of employees. The 21 -item scale instrument was designed to measure the perceptions of 
participants toward crisis or disaster preparedness. The reliability of this instrument was highly acceptable, which Cronbach's alpha score of 0.88 . The questionnaire consisted of two major parts including the basic characteristics of organizations and the perceptions on the likelihood of major crises. For the basic characteristics, eight demographic variables were included as follows: "types of organization", "number of employees at respondent's work location", "total number of organization employees worldwide, respondent's employment state", "respondent's gender", "size of city of respondent's work location", "number of total organizational locations worldwide", and "respondent's position in the organization." For the perceptions on the likelihood of major crises, the five types of crises included in the questionnaire were as follows: "secondary terrorist attack", "natural disaster", "major terrorist attack", "accidental disaster", and "workplace violence." Unlike other studies in the past, this study did not only focus on the top management in organizations, but also surveyed other levels in organizations as well because the top executives are more likely to provide information that supports the preparedness of crisis in their organizations. The sample of this study was selected from the alumni database from AACSB-accredited College of business in a state university in the south-western United States. The questionnaire was sent by mail to 2,283 alums. The response rate of the complete and usable questionnaire was $18.27 \%$. For statistical analysis, this study used ANOVA to compare the perceived preparedness for a crisis prior to the actual event occurring in terms of management levels, organizational size, type of industry, and population density of an organization's location. The results indicated that the top management had a higher perception of crisis preparedness than typical employees. There were no significant differences in perceptions on crisis preparedness in terms of size of the city where organizations were located. In addition, this study also found that public organizations had a higher perceived organizational preparedness for crisis than private organizations. Besides, organizations employed more than 500 employees showed the highest perception of crisis preparedness.

Sinha et al. (2008) evaluated the level of knowledge about disaster preparedness and mitigation among 375 undergraduate medical students by using the questionnaire. This study indicated that participants had little knowledge about disasters and disaster preparation and prevention. The study concluded that when discussed about the answers given by the students, it became clear that no knowledge was informed to students concerning disaster preparation and prevention. The students' knowledge about disaster preparedness and mitigation was based on their previous selflearned experiences and self-acquired about disaster.

Najafbagy (2011) studied the capabilities of crisis response and readiness at 41 Iranian hospitals by conducting interviews and asking questions to directors and generals. The results demonstrated that most of respondents were not acquainted with what was involved in crisis management even though they reported that their hospitals had crisis management plan in place. This study concluded that having crisis management plan solely was not enough if people in a specific organization did not have enough knowledge on how to implement it in the certain problem. Additionally, this study also indicated that the older mangers were accustomed to crisis management, and took crisis events and incidents more critically than younger ones.

Johansen, Aggerholm, and Frandsen (2012) also examined perceptions of organizational crisis management and communication among top management, middle management to employees in private and public organizations in Denmark. They conducted a large survey of internal crisis management and crisis communication among 98 public and 367 private organizations in Denmark. They applied a strategic, proactive and process oriented approach to crisis management and communication as the theoretical framework of the survey. Based on an assumption of theory of internal stakeholders, employees are viewed as stakeholders who have a psychologically stronger relationship to the organization than other stakeholder group (Frandsen and Johansen, 2011). This assumption was applied to develop one of research questions in this study to compare the differences of perceived organizational crisis management and communication between management and employees.

The aims of this study were to receive the basic information and idea and to better understand how these organizations view, plan, manage, and implement internal crisis management and communication activities in three different stages of crisis including before, during, and after. This research focused on four areas, which are 1) organizational crises in general; 2) the typical patterns of reaction and typical perception of causes, development and consequences in crisis situations among the management and employees; 3 ) the formal crisis preparedness in terms of crisis management and crisis communication; and 4) the quality of the organizations' formal internal crisis preparedness and the need to improve the preparedness. Their 36-questions survey questionnaire, which later was named as ICMCC survey was delivered to participants who were responsible for crisis preparedness in organizations, such as chief communication officers, human resource managers and/or other managers responsible for the crisis preparedness of the organization. This study used correlation analysis to explore the relationship between organizational characteristics and having a crisis plan. The findings showed the strong relationship between organizational size and crisis management, which the larger organizations were more likely to have a crisis management plan than the smaller ones, especially for 
private organizations. In addition, this study also found the relationship between an educational level of the crisis manager and crisis management practices, in particular the results indicated the positive relationship between level of education of the crisis manager and crisis management plan only for private companies.

Based on literature reviews, the crisis management process focused on three crucial preevent factors, which are environmental context including institutionalized practices and industry regulations, executive perceptions about risk, and adoption of organizational crisis management preparations (Pearson and Clair, 1998). As this model placed its emphasis on crisis management outcomes either success or failure, these three contributing factors had affected and determined the degree of organizational success and failure from crisis. Fowler, Kling, and Larson (2007) developed their research hypotheses based on these three constructs. They placed the emphasis on finding the differences on perception of organizational crisis preparedness in terms of position in the organization, population density where the organization is located, types of organization, and number of employees. Their research's findings showed the significant differences on perception between executives and employees, and the number of employees. Johansen, Aggerholm, and Frandsen (2012) also included crisis education variable on their study to find the relationship between level of crisis education and crisis management and communication.

\section{Research Methodology}

This study was exploratory empirical study that describes the levels of perceived organizational preparedness of employees who worked at the paper packaging company in Thailand. Data were gathered from 250 employees of the paper packaging company in March, 2014 by using the simple random sampling technique. Of these, only 233 participants completed the questionnaire, resulting in response rate of $93.2 \%$. A perceived organizational crisis preparedness scale was developed based mainly on a 21-item crisis/ disaster preparedness scale created by Fowler, Kling, and Larson (2007). Their scale covered five key areas of crisis including secondary terrorist attack, natural disaster, major terrorist attack, accidental disaster, and workplace violence. Additionally, the relevant concepts of organizational crisis preparedness from Dinkin (2007) and Bernstein (2012) were included as additional items in a modified scale. A total of 30-item for a perceived organizational crisis preparedness was finalized and tested for validity and reliability. To ensure the meaning of each item when translated into Thai language, a reversed translation was done by a professional translator. In addition, the index of item-objective congruence (IOC) was used to evaluate the content validity of each item of the scale. A total of 5 experts in related fields were asked to evaluate the score for each item. The IOC score of more than 0.5 was acceptable. For this instrument, there was no item received a score less than 0.5.

In addition, Exploratory Factor Analysis (EFA) was used to determine the number of factors to remain. Compatibility of data for EFA was assessed with Barlett's test of Sphericity and Kaiser-Meyer-Olkin (KMO). If KMO was greater than 0.5, and the Barlett's test was significant, the data would be suitable as compatible for EFA. In this study, KMO was 0.930, and Barlett's test was significant (Chi-square $=3914.393, p=0.000$ ), which were acceptable for utilizing EFA technique. Factor extraction was done to determine the number of factors by using principal component analysis and varimax. The result revealed that five factors had Eigen value greater than 1 with $60.4 \%$ cumulative of variance. The factor loadings of organizational crisis preparedness scale were from 0.464 to 0.725 , which were acceptable since the factor loading of each item was greater than 0.3 . However, the purpose of this study was to compare mean differences not to develop theoretical framework, therefore, measurement of perceived organizational crisis preparedness as a whole was preferable. A final version of perceived organizational crisis preparedness scale comprised of 30-item with a 4-point rating scale (1-4). Participants were asked to rate each item of scale to the extent in which each characteristics described them properly. The rating scale of perceived organizational crisis preparedness scale were $1=$ "strongly disagree", $2=$ "disagree", 3 = "agree" and, 4 = "strongly agree". This instrument had a Cronbach's alpha of 0.95 , which was highly acceptable.

\section{Results}

Demographic and organizational factors of sample respondents indicated that the majority of respondents was female (66.5\%). For employment state, the largest group of sample was employee (93.1\%) while the executives were a small size (6.9\%). For the work experience, the majority of participants had work experience between 1-10 years (64.8\%), followed by $11-20$ years (27\%), and more than 20 years (8.2\%). For education in crisis management, employees with education in crisis management were $72.5 \%$ whereas $27.5 \%$ of them were not provided. In addition, the mean of perceived organizational crisis preparedness level as a whole evaluated by respondents was interpreted as "agree" ( $M=$ 3.15 , S.D. $=.443$ ). As shown on the mean score, the top three items prioritized by respondents included "I know where 
the nearest emergency exits are to my desk/ workstation" (M = 3.32, S.D. $=.637)$, "All organization members are required to rehearse portions of our crisis plan, for example, evacuation" (M = 3.35, S.D. =.646), and "All organization suffered a serious crisis; I would still have my job" (M = 3.30, S.D. $=.671)$

To compare mean differences of demographic and organizational variables, independent t-test analysis and analysis of variance (ANOVA) were used to compare the difference levels of perceived organizational crisis preparedness of Thai employees in terms of employment state, education in crisis, and work experience. Analysis of independent t-test indicated that executives had a higher level of perceived organizational preparedness than employees $(t=4.482, p=$ 0.01) (see Table 1). Due to the significant level achieved for this variable was lower than 0.05, Hypothesis 1: Executives will have a higher perception of organizational crisis preparedness than the employee, was accepted.

Table 1. Independent t-test for Perceived Organizational Crisis According to Employment State $(n=233)$

\begin{tabular}{|c|c|c|c|c|c|c|}
\hline \multirow{2}{*}{ Variables } & \multicolumn{2}{|c|}{$\begin{array}{c}\text { Executives } \\
(\mathbf{n}=16)\end{array}$} & \multicolumn{2}{c|}{$\begin{array}{c}\text { Employees } \\
(\mathbf{n}=217)\end{array}$} & \multirow{2}{*}{$\mathrm{t}$} & \multirow{2}{*}{$\mathrm{p}$-value } \\
\cline { 2 - 5 } & Mean & S.D. & Mean & S.D. & & \\
\hline Perceived Organizational Crisis Preparedness & 3.4 & .397 & 3.13 & .449 & 4.482 & $0.000^{\star *}$ \\
\hline$*$ Significant level at 0.01
\end{tabular}

Table 2 showed no significant difference in work experience $(F=.874, p=.713)$. No pairwise comparisons were conducted because there was no significant mean difference in this area of analysis. Due to the significant level achieved for this variable was greater than 0.05, therefore, Hypothesis 2: Employees with more work experience will have higher perception of organizational crisis preparedness than employees with less work experience, was rejected.

Table 2. One-Way Analysis of Variance (ANOVA) for Perceived Organizational Crisis According to Work Experience

\begin{tabular}{|c|c|c|c|c|c|}
\hline & Sum of Squares & df & Mean Square & F & Sig. \\
\hline Between Groups & 19.965 & 54 & .370 & .874 & .713 \\
\hline Within Group & 75.254 & 178 & .423 & & \\
\hline Total & 95.219 & 232 & & & \\
\hline
\end{tabular}

Table 3 indicated significant difference between employees for education in crisis, which employees with education crisis had a higher level of perceived organizational preparedness than employees without education crisis $(t=4.425, p=$ 0.01). Due to the significant level achieved for this variable was lower than 0.05 , Hypothesis 3: Employees with education in crisis management will have a higher perception of organizational crisis preparedness than employees with no education in crisis management, was confirmed.

Table 3. Independent t-test for Perceived Organizational Crisis According to Education in Crisis $(n=233)$

\begin{tabular}{|c|c|c|c|c|c|c|}
\hline \multirow{2}{*}{ Variables } & \multicolumn{2}{|c|}{$\begin{array}{c}\text { Employees with Education in } \\
\text { Crisis } \\
(\mathbf{n}=169)\end{array}$} & $\begin{array}{c}\text { Employees with No } \\
\text { Education in Crisis } \\
(\mathbf{n}=64)\end{array}$ & \multirow{2}{*}{$\mathbf{t}$} & \multirow{2}{*}{$\mathbf{p}$-value } \\
\cline { 2 - 8 } & Mean & S.D. & Mean & S.D. & & \\
\hline Perceived Organizational Crisis Preparedness & 3.22 & .426 & 2.95 & .426 & 4.425 & $0.000^{* *}$ \\
\hline
\end{tabular}

${ }^{*}$ Significant level at 0.01

\section{Discussion and Conclusion}

In sum, the result of independent t-test analysis indicated the significant mean differences in employment state and education in crisis. Thus, research hypotheses \# 1 and \# 3 were accepted. On the other hand, the result of analysis of variance (ANOVA) showed the insignificant mean difference in work experience. Therefore, research hypothesis \# 2 was rejected.

In research hypothesis \# 1, this study found significant mean difference between executives and employees in perception toward organizational crisis preparedness. This finding was consistent with the results of Fowler, Kling, and Larson's study (2007), which indicated that the top management had a higher perception of crisis preparedness than typical employees. This may be because executives who are in the top level of management are required to think 
holistically and get involved with process of planning and strategic management, therefore, they are more likely to be aware of organizational crisis preparedness than typical employees. However, the classification of management levels should be extended in order to empirically explore the different levels of perceived organizational crisis preparedness among those levels.

In research hypothesis \# 2, this study found no significant mean difference in work experience on perceived organizational crisis preparedness. The finding of this study was inconsistent with Najafbagy's study (2011), which reported that the older mangers were accustomed to crisis management, and took crisis events and incidents more critically than younger ones. In other words, the more experienced employees were more likely to perceive organizational crisis preparedness differently than less experience employees. This finding did not support the controversy that employees who had more work experience in the organization were more likely to familiar with the crisis preparation (Fowler, Kling, and Larson, 2007). Controversially, the different levels of perception towards organizational crisis preparedness did not depend on work experience due to the willingness of employees to improve capabilities to effectively respond to crisis, and area of responsibilities.

In research hypothesis \# 3, this study discovered significant mean difference in education in crisis management. This finding was new knowledge. Even though the study of Johansen, Aggerholm, and Frandsen (2012) found the relationship between an educational level of the crisis manager and crisis management practices, in particular the results indicated the positive relationship between level of education of the crisis manager and crisis management plan only for private companies, they did not thoroughly compare or examine the difference of crisis management practice in terms of education in crisis. Obviously, employees with education in crisis were more likely to view organizational crisis preparedness differently than employees who were not provided education in crisis. Clear understanding of crisis management plan and preparation in the organization is based on knowledge; if employees are not educated properly they are less likely to cope with crisis effectively.

There were some limitations for this study. The generalization of this study was not applicable as respondents were drawn solely from a selected company in Thailand. As other perceptions may exist with employees from different companies in the distinctive industries in Thailand, the further study should investigate other companies in different industries. In addition, another limitation of this study was variables. This study analyzed only three demographic and organizational variables when compared difference of mean score. The future study should add more variables that are relevant to crisis preparation such as experience in crisis, educational levels of respondents, etc. Moreover, limitation of this study was to focus on an analysis of private organization rather than public organization. Future research should examine the comparison of the different types of organization.

\section{References}

Alas, R., Gao, J., \& Vanhala, S. (2010). The crisis management in Chinese and Estonian organizations. Chinese Management Studies, 4(1). Retrieved from ProQuest Database

Alba, D. J. \& Gable, R. K. (2011). Crisis preparedness: Do school administrators and first responders feel ready to act? NERA Conference Proceedings 2011. Paper 7. Retrieved from http://digitalcommons.uconn.edu/cgi/ viewcontent.cgi?article=1006\&context=nera_2011

Ashcroft, L. S. (1997). Crisis management - public relations. Journal of Managerial Psychology, 12(5). Retrieved from ProQuest Database.

Augustine, N. R. (1995). Managing the crisis you tried to prevent. Harvard Business Review, 73(6), 147-158.

Barton, L. (1993). Crisis in organizations: managing and communicating in the heat of chaos. Cincinnati, OH: South-Western Publishing Company.

Barton, L. (2001). Crisis in organizations II. Cincinnati, OH: South-Western College Publishing - Thomson Learning.

Barton, L. (2008). Crisis leadership. New York, NY: McGraw-Hill.

Bernstein, J. (2012). Manager's guide to crisis management. Madison, Wl: McGraw-Hill.

Blythe, B. T. (2004). The human side of crisis management. Retrieved from http://www.cmiatl.com/news_article63.html

Borodzicz, E. P. (2005). Risk, crisis and security management. England: John Wiley \& Sons Ltd.

Chong, J. (2004). Six steps to better crisis management. Journal of Business Strategy, 25(2). Retrieved from ProQuest Database.

Chong, J. \& Nyaw, M. (2002). Are Hong Kong companies prepared for crisis? Disaster Prevention and Management, 11(1). Retrieved from ProQuest Database.

Coombs. W. T. (2007). Ongoing crisis communication: planning, managing, and responding. Thousand Oaks, CA: Sage Publication.

Conte, C., Myer, R. A., Miller, J. A., \& D'Andrea, L. (2007). Assessing human impact of organizational crises: reliability and validity of the Triage Assessment Scale for Organizations (TAS:0). Journal of Contingencies and Crisis Management, 15(3), 134-142.

Daft, R. L. \& Marcic, D. (2009). Management: the new workplace (6 $6^{\text {th }}$ ed.). International Edition: South-Western.

Delvin, E. S. (2006). Crisis management, planning, and execution. Boca Raton, FL: Auerbach Publications. 
Dinkin, D. R. (2007). Organizational crises in local North Carolina public health agencies: a crisis typology and assessment of organizational preparedness. Unpublished doctoral dissertation, North Carolina, U.S.A. Retrieved on February 7, 2014 from UMI ProQuest Digital Dissertation.

Eriksson, K. (2010). Preparing for preparedness - shaping crisis planning process in local authorities. Unpublished doctoral thesis, Lund University, Sweden. Retrieved on April 13, 2014 from

http://lup.lub.lu.se/luur/download?func=downloadFile\&recordOld=1716820\&fileOld=1939737

Fearn-Banks, K. (1996). Crisis communication: a casebook approach. Mahwah, NJ: Lawrence Erlbaum Associates Publishers.

Fowler, K. L., Kling, N. D., \& Larson, M. D. (2007). Organizational preparedness for coping with a major crisis or disaster. Business and Society, 46(1). Retrieved from ProQuest Database.

Frandsen, F. \& Johansen, W. (2011). The study of internal crisis communication: towards an integrative framework. Corporate Communications: An International Journal, 16(4), 347-361.

Gottschalk, J. (2002). Crisis management. Oxford, United Kingdom: Capstone Publishing.

Hargis, M. \& Watt, J. D. (2010). Organizational perception management: a framework to overcome crisis events. Organizational Development Journal, 28(1). Retrieved from ProQuest Database.

Isaraeli, A. A. (2007). Crisis-management practices in the restaurant industry. Hospital Management, 26, 807-823.

Jaques, T. (2010). Embedding issue management as a strategic element of crisis prevention. Disaster Prevention and Management, 19(4), 469-482.

Johansen, W., Aggerholm, H. K., \& Frandsen, F. (2012). Entering new territory: a study of internal crisis management and crisis communication in organizations. Public Relation Review, 38. Retrieved from ProQuest Database.

Kash, T. J. \& Darling, J. R. (1998). Crisis management: prevention, diagnosis and intervention. Leadership \& Organization Development Journal, 19(4). Retrieved from ProQuest Database,

King, III, G. (2002). Crisis management \& team effectiveness: a closer examination. Journal of Business Ethics, 41(3), $235-249$.

Lalonde, C. (2007). Crisis management and organizational development: towards the conception of a learning model of crisis management. Organizational Development Journal, 25(1). Retrieved from ProQuest Database.

Lerbinger, O. (1997). The crisis manager: facing risk and responsibility. Mahwah, NJ: Lawrence Erlbaum Associates Publishers.

Lin, W. B. (2013). Factors affecting development of crisis management mechanism in hospitals. Quality \& Quantity, 47(3), $1445-1457$.

Lockwood, N. R. (2005). Crisis management in today's business environment: HR's strategic role. Retrieved from

http://www.shrm.org/research/articles/articles/documents/1205rquartpdf.pdf

Lussier, R. N. \& Achua, C. F. (2007). Effective leadership (3rd ed.). Mason, OH: Thomson.

McCray, J. P., Gonzalez, J. J., Darling, J. R. (2010). Crisis management in smart phones: the case of Nokia vs Apple. European Business Review, 23(3). Retrieved from ProQuest Database.

Meznar, D. (2012). Crisis management - tools for restructuring of companies as a response to global crisis situations. Asian Journal of Business and Management Science, 1(11). Retrieved from http://www.ajbms.org/articlepdf/ajbms201211i11106.pdf

Mitroff, I. I., Diamond, M. A., \& Alpaslan, C. M. (2006). How prepared are America's colleges and universities for major crises? Change, 38(1). Retrieved from Ebscohost database.

Myer. R. A., Conte, C. \& Peterson, S. E. (2007). Human impact issues for crisis management in organizations. Disaster Prevention and Management, 16(5). Retrieved from ProQuest Database.

Najafbagy, R. (2011). The crisis management capabilities and preparedness of organizations: a study of Iranian Hospitals. International Journal of Management, 28(2). Retrieved from ProQuest Database.

Nickerson, A. B. \& Zhe, E. J. (2004). Crisis prevention and intervention: a survey of school psychologist. Psychology in the Schools, 41(7), 777-788.

Ocal, E., Oral, E. L., \& Erdis, E. (2006). Crisis management in Turkish construction industry. Building and Environment, 41, $1498-1503$.

Parsons, W. (1996). Crisis management. Career Development International, 1(5). Retrieved from ProQuest Database .

Pauchant, T. C. \& Mitroff, I. I. (1992). Transforming the crisis-prone organization: preventing, individual, organizational, and environmental tragedies. San Francisco, CA: Jossey-Bass Publishers.

Pearson, C. M. \& Clair, J. A. (1998). Reframing crisis management. Academy of Management Review, 23(1). Retrieved from ProQuest Database.

Pillsburylaw (2011). 2011 crisis preparedness survey results. Retrieved from http://www.pillsburylaw.com/siteFiles /Publications/2011CrisisResultsfinal.pdf

Pheng, L. S., Ho, D., \& Ann, Y. (1999). Crisis management: a survey of property development firms. Property Management, 17(3). Retrieved from ProQuest Database.

Sapriel, C. (2003). Effective crisis management: tools and best practice for the new millennium. Journal of Communication Management, 7(4). Retrieved from ProQuest Database.

Sinha, A. \& Pal, D. K., Kasar, P. K., Tiwari, R.., \& Sharma, A. (2008). Knowledge, attitude and practice of disaster preparedness and mitigation among medical students. Disaster Prevention and Management, 17(4), 503-507.

Smits, S. J. \& Ally, N. E. (2003). "Thinking the unthinkable" - leadership's role in creating behavioural readiness for crisis management. Competitiveness Review, 13(1). Retrieved from ProQuest Database.

Spillan, J. E. \& Crandall, W. (2001). Crisis planning among Guatemalan small businesses: the assessment of worst-case scenarios. The Journal of Business in Developing Nations, 5, 21-55.

The Institute of Internal Auditors. (2011). Three crisis management imperatives for CAEs. Retrieved from www.theiia. 
org/download.cfm?file $=77070$

Ulmer, R. R., Sellnow, T. L., \& Seeger, M. W. (2007). Effective crisis communication: moving from crisis to opportunity. Thousand Oaks, CA: Sage Publications.

Wallace, M. \& Webber, L. (2010). The disaster recovery handbook: a step by step plan to ensure business continuity and protect vital operations, facilities, and assets ( $2^{\text {nd }}$ ed.). New York, NY: AMACOM. 